\title{
OS NOVOS SISTEMAS DE ENSINO DA ARTE: K. MALIÉVITCH E A REVOLUÇÃO ARTÍSTICO-PEDAGÓGICA NA RÚSSIA
}

\author{
Angela Nucci \\ Mestranda em História da Arte ${ }^{1}$ \\ Instituto de Filosofia e Ciências Humanas - UNICAMP
}

As Revoluções de 17, apoiadas por muitos artistas, ajudaram a reforçar uma série de idéias no campo da arte que incluíam o culto ao novo, a aversão à cópia e aos modelos do passado e a condição irrevogável da liberdade de criação artística. Neste contexto, os moldes "opressores" da Academia eram insustentáveis.

$\mathrm{Na}$ esfera cultural, fazia-se necessária a realização de um programa artístico coerente com os ideais da recém vitoriosa revolução socialista; cidades e ruas foram rebatizadas, a destruição em praça pública dos monumentos e símbolos do czarismo tornou-se ordem do dia. A política cultural de "propaganda dos monumentos" proposta por Lênin instituía a substituição dos monumentos czaristas por novas obras que homenageassem os heróis da revolução e da nova sociedade, em uma lista que ia de Marx a Cézanne.

Todavia, não poucas contradições marcaram esse período de transformações. Desde a revolução de fevereiro, vários grupos artísticos mobilizaram-se para que um órgão responsável pelos assuntos artísticos fosse eleito por eles, de forma que a vida artística do país estivesse sob o controle dos próprios artistas; ao Estado, por sua vez, caberiam as tarefas de financiamento e controle geral. Porém, as divergências estéticas e disputas entre os artistas constituíam um entrave às exigências centralizadoras de um regime que visava à coletivização da produção artística.

A nova forma de organização foi definida no início de 1918 com a criação do Narkompros: o Comissariado do povo à instrução, sendo este dividido em várias seções, dentre elas a Teo (Seção Teatral), a Muzo (Seção Musical) e a Iそo (Seção de Artes Plásticas). Esta última dividia-se em subseções: pedagógica, de arquitetura, do cinema, de produção artística, de edição artística, de trabalhos artísticos e de decorações teatrais.

\footnotetext{
${ }^{1}$ Pesquisa de mestrado financiada pela Capes e pela Fapesp.
} 
Sob a direção de Anatoli Lunatcharski, o Comissariado buscava mediar a rivalidade existente entre as diferentes correntes, abrindo espaço aos artistas na organização do novo sistema cultural. Lunatcharski via-se ainda diante da difícil tarefa de mediar a realização de um conjunto de projetos inovadores em um contexto no qual a grande maioria da população era iletrada, o que, portanto, implicava em reconhecer que esta população não tinha a real dimensão das tradições culturais que estavam sendo rechaçadas pela vanguarda emergente. Em contrapartida, ao se ocupar da decoração de espaços e espetáculos populares, ao assumir cargos no interior de instituições estatais e tendo suas obras adquiridas pelo governo, artistas como Maliévitch, Tatlin, Altman, Exter e Popova garantiram, mesmo que por um curto período, a ligação da arte de vanguarda à imagem do novo regime.

Compartilhando da premissa de que a aquisição de que um "certo nível de cultura" era indispensável à construção do socialismo, o conceito de instrução, peça chave da política do Narkompros, era concebido por Lunatcharski em um panorama que muito além dos aspectos básicos da formação cultural (como a alfabetização) relacionava-se a tarefa de difusão ideológica do socialismo e a consolidação de uma cultura proletária. Assim, coube a Izo lidar com uma série de questões teóricas e práticas relacionadas ao posicionamento das artes plásticas frente ao projeto sócio-político soviético.

A Izo foi responsável por ações que incluíam a organização de exposições, a criação de museus e institutos de pesquisa artística e a compra de obras. Várias políticas de difusão da cultura foram implementadas pela Seção, através de medidas como a publicação de livros de vulgarização da História da Arte, a organização de conferências destinadas aos operários, a organização de exposições gratuitas e nas ruas, a decoração de espaços públicos nas festas comemorativas, a ilustrações de livros, etc.

A partir de 1918, assiste-se o surgimento de uma série de instituições de ensino artístico na Rússia. Em linhas gerais, este conjunto de institutos tentava atender as premissas do projeto artístico-pedagógico da Izo que contemplava as seguintes metas: a formação pedagógica como forma de criar um contingente de docentes, a ênfase na formação técnica, a 
criação de trabalhos no domínio da arte produtiva e o estabelecimento de institutos voltados à pesquisa teórica e científica da arte. ${ }^{2}$

O primeiro passo nesse sentido foi dado quando as antigas academias de arte foram substituídas pelos Ateliês nacionais livres (renomeados em 1919, como Svomas) que se espalharam por uma série de cidades do antigo Império russo.

Do ponto de vista administrativo, era assegurado a todo cidadão de mais de dezesseis anos o direito de se inscrever, o curso era gratuito tendo a duração máxima de sete anos. Cada grupo tinha à sua frente um ou mais professores divididos de acordo com sua tendência (os professores podiam ser eleitos pelos alunos ou previamente designados e existiam ainda ateliês funcionando sem a supervisão de professores). O curso compreendia uma jornada de seis horas diárias: durante o dia eram ministradas disciplinas de artes e durante a noite, as disciplinas artístico-científicas ${ }^{3}$, obrigatórias àqueles que desejassem obter a formação pedagógica.

Lecionando no Svomas, Maliévitch definia seu programa do ano escolar de 1919-1920 da seguinte forma:

$\mathrm{O}$ ateliê compreende duas divisões: pintura e escultura. Tendência geral do ateliê: Cubismo, Futurismo, Suprematismo como novo realismo da concepção pictórica do mundo.

Tema n. 1- Grupo 1: abstração dos objetos, os volumes pictóricos e escultóricos, a superfície, a reta, linha fragmentada (curso preparatório do cubismo).

Tema n. 2- Grupo 2: 1) Cézanne, sua concepção pictórica do mundo. 2) A teoria cubista e o sistema de construção das formas. 3) A fatura pictórica. 4) Espaço e forma. 5) A natureza no sistema cubista. 6) O volume, a superfície, a reta, a linha fragmentada no sistema cubista. 7) Cubismo e natureza; estática e dinâmica. 8) Sistema pictórico dos elementos coloridos, pesos da forma e da construção.

Tema n. 2: escultura. Construção de formas segundo o sistema cubista.

Tema n. 3: Futurismo. Grupo 3: 1) Van Gogh, sua dinâmica e sua concepção do mundo. 2) Futurismo e natureza: a cidade e o campo. Elementos urbanos e rurais como fatores influindo na construção do momento dinâmico. 3) Teoria do Futurismo. 4) Academia e Futurismo. 5) Fatura pictórica e dinâmica. 6) Construção de elementos formais dos objetos segundo o sistema do Futurismo.

2 Após a criação dos Svomas, seguiu-se a abertura dos Ateliês superiores de arte e técnica (Vkhutemas, 1920-1928) substituídos pelo Instituto superior de arte e técnica (Vkbutein, 1929-1930); o Instituto de Cultura Artística (Inkbuk, 1920-1922) e o Instituto nacional da cultura artística de PetrogradoLeningrado (Guinkbuk, 1924-26); Academia Russa das Ciências da Arte (Rakhn, 1921-1925) renomeada Academia nacional das ciências das artes (Gakbn, 1925-1930). Ressalta-se ainda a formação do Museu da Cultura pictórica de Moscou e do Museu da Cultura artística de Petrogrado.

${ }^{3}$ Sendo essas: História da arte do Ocidente, da Rússia e contemporânea, História das artes decorativas, Filosofia da arte, Metodologia de ensino das artes plásticas, Anatomia plástica, Perspectiva, Teoria das sombras e geometria descritiva. 
Tema n. 4: Suprematismo - Grupo 4: 1) Teoria do suprematismo. 2) Fatura dinâmica, pictórica e colorida. 3) Construção dinâmica das formas. 4) A forma, o espaço e o tempo. 5) A cor como arte bidimensional. 6) A cor e a cidade. 7) Construção de formas segundo o sistema do Suprematismo. 4

Durante os anos 20, o projeto de construção de um modo de vida coletivo relacionava-se a uma série de questões que incluíam a construção de uma sociedade mais igualitária, o que na esfera das relações de trabalho pode ser exemplificado pela busca de uma equivalência entre as profissões. Em ressonância a este contexto, muitos artistas trabalharam dentro de propostas coletivas que não distinguissem hierarquias entre artes menores e maiores, artistas e artesãos, visando uma formação global destes novos profissionais.

Dentre os vários exemplos do período, o Manifesto do comitê de criação do Unovis (Otverditelei novogo iskusstvo - Afirmadores da nova arte), coletivo fundado por Maliévitch no interior dos Svomas de Vitebsk (19191922), convocava:

[...] à ação, ao voto e ao movimento, não somente os produtores de arte, mas também [os] camaradas ferreiros, montadores, caldeireiros, pedreiros, betoneiros, carpinteiros, fabricantes de máquinas, pilotos, entalhadores, mineiros, trabalhadores têxteis, alfaiates, costureiras e todos os fabricantes de objeto do mundo utilitário $[. .]$.

Assim, sob a tônica de reunir criação e técnica sem distinções hierárquicas surgem no final de 1920, da fusão dos Primeiros e Segundos Ateliês nacionais livres de arte, os Vkhutemas, que incluíam o ensino da pintura, escultura, arquitetura, cerâmica, artes gráficas, artes aplicadas, etc.

Embora o ensino das diversas disciplinas não fosse compartimentado dentro dos Vkhutemas, a diminuição de admissões nos cursos de pintura e escultura acompanhada do aumento de vagas nas faculdades de produção revela o apelo industrial da arte na época. Tal tendência confluiu na criação de instituições como a Academia russa das ciências da arte e o Instituto estatal de cultura artística, dirigidas

${ }^{4}$ K. S. Malévitch, "Au Soviet des Seconds Ateliers Nationaux d'Art Libres" (Programma zaniatii v masterskikh utchebnogo 1919 i 1920 goda), 15 de setembro de 1919. TsGALI, fundo 681, inv. 1, dos. 845, p. 353. In KHAN-MAGOMEDOV, S., Vhutemas-Moscou 1920-1930, vol. I, Paris: Editions du regard, 1990, p. 197.

${ }^{5}$ Manifesto do Comitê de Criação do Unovis. "DE LA PART DE L'OUNOVIS. ALLONS SUR LA ROUTE DE L'UNIQUE AUDITOIRE PICTURAL. NOUS SOMMES PLAN, SYSTEME, ORGANISATION. DIRIGEZ VOTRE CREATION SUR L'APLOMB DE L'ECONOMIE", Vitebsk, 1919-1920. In MALÉVITCH, K. S., Le Miroir Suprematiste - Tous les articles parus en russe de 1913 a 1928, avec des documents sur le suprematisme, Lausanne: L'Âge d'Homme, 1977, p. 87. 
respectivamente por Kandinski e Maliévitch, artistas outrora afastados de institutos moscovitas por divergências ideológico-artísticas, seja no que concerne ao apelo espiritual ou místico de suas teorias ou pelas práticas experimentais de pesquisa artística.

A crítica à chamada arte "experimental" pode ser entendida no contexto das reformas promovidas nos anos da NEP (Nova Política Econômica). A necessidade emergente de modernização da Rússia daria impulso a uma série de medidas que incluíam a instituição do ensino gratuito em todos os seus níveis, o ensino a distância e noturno e a formação técnica, como desenvolvida nas faculdades operárias (Rabfaks). Essa ligação entre indústria e criação coletiva era vista como fundamental ao desenvolvimento do país e representava, em contrapartida, o retorno do investimento estatal nos institutos.

No quadro da Iro, figuravam outras duas instituições voltadas à experimentação e análise dos fundamentos plásticos: o Instituto da Cultura artística (Inkhuk) de Moscou e o Instituto Nacional da Cultura Artística (Guinkhuk) de Petrogrado, que apesar de possuírem estruturas semelhantes abordavam de maneira diferente as questões do ensino e da aplicação das artes, diferenciando-se tanto em suas propostas metodológicas quanto ideológicas.

Sob a direção de V. Kandinski, o Inkhuk tinha como projeto o estudo científico das diversas manifestações artísticas e suas possíveis interações visando uma síntese das artes. Sob severas críticas do Grupo de análise objetiva da arte (sob a direção de Rodtchenko) Kandinski foi afastado do Instituto, fundando logo em seguida, a Academia Russa das Ciências da Arte (Rakhn), onde desenvolveu suas pesquisas pedagógicas pela última vez na Rússia, antes de sua partida definitiva para Berlim, no fim de 1921 (onde assumiu o cargo de professor na Bauhaus, de 1922 a 1933).

O Guinkhuk de Leningrado, por sua vez, foi formado a partir do Museu da cultura artística de Petrogrado (MKHK), sob a iniciativa de K. Maliévitch e V. Tatlin. Tendo como proposta aliar as pesquisas teóricas e práticas dos professores e alunos, o ensino e a crítica das artes, as duas instituições passaram a funcionar como uma espécie de complexo cultural a partir de 1925. Esta união entre o museu e os laboratórios de pesquisa tinha por objetivo promover o livre acesso dos alunos às obras contemporâneas e facilitar a aprendizagem destes. Dentro desta nova perspectiva, o museu não se constituiria mais como um espaço contemplativo, mas como um organismo dinâmico que pudesse criar um sistema de divulgação das pesquisas e acolher em seu acervo as obras de seus jovens artistas, 
financiando e impulsionando a produção em um país que havia liquidado com seus marchands e colecionadores.

No Guinkhuk, os artistas-professores buscaram criar métodos críticos e pedagógicos de inteligibilidade das artes por meio de processos de criação, experimentação e investigação científica da cultura artística. As abordagens subjetivas ou que se fundamentavam em fatos psicológicos, biográficos ou históricos foram suplantadas pela investigação dos elementos que compõem o vocabulário plástico, dentre eles: linha, ponto, plano, volume, cor, espaço, relação de planos, forças, tensões, ritmos, movimento, relações dinâmicas, estáticas e a inter-relação destes elementos na composição.

As pesquisas no Guinkhuk eram desenvolvidas em sete seções. Além das quatro seções principais, existiam ainda laboratórios secundários como a Seção experimental dirigida pelo pintor Pavel Mansurov e a seção dedicada ao estudo da fonologia, dirigida pelo poeta Igor Terentiev. Estes laboratórios anexos não eram considerados oficiais, motivo pelo qual seus diretores, assim como os demais colaboradores científicos, não tinham o direito à remuneração.

As quatro seções principais do Guinkhuk eram:

- Seção da Cultura Orgânica, dirigida por Matiuchin com colaboração científica de Boris, Maria e Xênia Ender e dedicada ao estudo da percepção dos elementos artísticos, como cor, volume e espaço;

- Seção da Cultura Material, dirigida por Tatlin até 1925, era dedicada à pesquisa dos elementos construtivos e materiais e voltava-se à elaboração de modelos à nova arte industrial. Com a partida de Tatlin para Kiev, foi transformada em Departamento de Arquitetura Suprematista, sendo depois renomeado Laboratório da Ordem Suprematista. Sob a direção de Nicolai Suétin esta faculdade de arquitetura compreendia o ponto mais alto do projeto pedagógico de Maliévitch;

- Seção da Ideologia Geral da Arte teve a principio Filonov como seu diretor, o qual desenvolveu uma teoria fundada sobre o estudo dos materiais. Entre 1925 e 1926, sob o nome de Departamento da Metodologia Geral da Arte, foi chefiado por Nicolai Punin;

- Seção Teórica e Formal (FTO) foi renomeada como Departamento da Cultura Pictórica e esteve sob a direção de Maliévitch, tendo como colaboradores científicos Vera Ermolaieva, Liev Iudin e Lazar Khidekel. Era subdividido no laboratório da cor, com Vera Ermolaieva a sua frente e no laboratório da forma, dirigido por Iudin. Neste local Maliévitch e seus alunos desenvolveram uma teoria crítica e pedagógica que 
visava analisar uma série de sistemas artísticos da época. O resultado deste trabalho foi a Teoria do elemento adicional em pintura.

Com a formação dos quadros docentes por integrantes da vanguarda, a produção artística passou na década de 20 por uma espécie de "institucionalização" ou "legitimação acadêmica". No entanto, a transição do manifesto à produção científica foi em essência a passagem da "afirmação" à "análise" através da sistematização do conhecimento artístico em teorias, tratados e metodologias de ensino e pesquisa.

O manifesto, enquanto texto de caráter emblemático foi o formato escolhido pelos artistas da vanguarda como meio de expressão mais coerente em um contexto de agitações ideológicas, de contestação dos cânones artísticos e de defesa da liberdade de criação. Transposto este momento e em resposta às exigências do período pós-revolucionário, os artistas se dedicaram ao desafio teórico de esclarecer a formação e os valores da nova cultura pictórica e de indicar caminhos para seu desenvolvimento. Assim, de uma posição informal (grupos de arte) e marginal (sob a alcunha de futuristas ${ }^{6}$ ), os artistas passaram a ocupar os cargos de pesquisadores e docentes, posição que seguiu uma lógica natural, visto que grande parte dos artistas da vanguarda russa sempre vinculou a pena ao pincel.

Contudo, quando se fala da produção teórica desenvolvida por grupos como o Unovis, a Lef, a Proletkult e a Opoiaz, é preciso levar em consideração o fato de que muitos dos princípios postulados, sobretudo nos anos subseqüentes à Revolução de 17 , não podem ser enquadrados rigorosamente dentro de uma produção científica. Sem excluir a importância teórica e o papel pioneiro de grande parte dos trabalhos, percebe-se ainda certo tom emblemático, de auto-afirmação, fruto de um ambiente marcado por disputas e oposições entre artistas de diferentes tendências.

Por outro lado, é certo que esse processo de institucionalização da arte esteve vinculado a interesses práticos como a qualificação profissional e a criação de mão-de-obra e de produtos para a indústria, mas a transformação do sistema cultural ofereceu vantagens materiais aos artistas (assim como a outros profissionais, dentre eles, professores, cientistas,

\footnotetext{
${ }^{6}$ A partir de 1913, o termo futurista passa a ser usado pela imprensa russa para designar de maneira generalizante as manifestações da vanguarda. Depois de 1917 os grupos vanguardistas de Moscou e São Petersburgo (cubo-futuristas e egofuturistas) passam a ser chamados de esquerdistas.
} 
engenheiros, médicos, etc.) que incluíam a organização de exposições sem júri e a compra de suas obras pelo Estado.

A adesão dos artistas à Iqo, não só favorável como necessária à realização de seus projetos, possibilitou a divulgação das obras a um novo público e a ampliação das áreas de atuação dos artistas, os quais de produtores de arte passaram também a articular os meios de acesso ao conhecimento artístico, como o ensino e crítica das artes e a organização dos Museus de cultura artística.

Segundo a pesquisadora Svetlana Djafarova (1993), de maio a novembro de 1918, um grupo de artistas vinculados a Izo, dentre estes: K. Maliévitch, O. Rozanova, V. Tatlin, V. Strzeminski e A. Pevsner trabalhou no projeto de criação de uma cadeia de museus de arte contemporânea na Rússia, os primeiros museus do gênero no mundo. Foi eleita uma comissão responsável pelas compras e ficou acertada a divisão das obras entre mais de trinta museus em diferentes cidades russas. De setembro de 1918 a dezembro de 1920, foram adquiridas (mesmo que a preços baixos) 1926 obras de 415 artistas, entre pinturas, esculturas, artes gráficas, etc. Os critérios de escolha dos trabalhos foram fixados em uma conferência realizada em 11 de fevereiro de 1919, no Palácio das Artes, em Petrogrado.

Como até então os museus se encontravam a serviço da nobreza, servindo, segundo a visão da vanguarda, como locais de conservação dos tesouros das elites, foi proposto que a escolha das obras não seria guiada por conceitos tradicionais da história da arte, juízos de gosto ou pelo tema, mas de acordo com a noção de cultura artística, que dava ênfase à experimentação e à criação no julgamento artístico. O ponto de partida de avaliação seria a própria obra e não sua ligação com determinado contexto histórico ou escola artística; deveriam ser levados em conta o aspecto inventivo, os valores pictóricos e formais e a fatura da obra.

O final da década de 10 foi prolífero em debates e projetos referentes à formação dos museus de cultura artística. As teses de Maliévitch, Nicolai Punin, Brik, Grichtchenko, entre outros artistas, buscavam redefinir a estrutura e o papel do museu enquanto espaço de criação, discutindo o acesso da população à vida cultural e a tarefa insubstituível do artista na organização de todos os campos da atividade artística.

Segundo as propostas de Maliévitch, era necessário unir a pesquisa artística, científica e pedagógica de maneira a formar um único complexo cultural. Neste sentido, o museu deveria ser concebido como um espaço de 
criação, extensão natural dos laboratórios de pesquisa, fornecendo o material às investigações dos novos artistas.

À frente do Museu de cultura artística de Petrogrado - MKHK (outubro de 1923 a outubro de 1924), Maliévitch propunha novos parâmetros de exposição das obras. Segundo ele, o museu contemporâneo deveria ser o reflexo dos projetos da época contemporânea e não um local de conservação ou acumulação de obras do passado:

Vejo o museu como um lugar onde o homem se encontra em todo um conjunto, onde cada um poderia ver a modificação, o crescimento e o desenvolvimento de todo um organismo e não examinar cada detalhe do todo em entrepostos isolados. $\mathrm{E}$ com isto, constituir a imagem do homem apenas com a forma contemporânea de sua última modificação e não sobrecarregar seus ombros com todos os mantos e togas do passado. ${ }^{7}$

Em parte tomada de empréstimo do Futurismo, a crítica ao museu "do passado" (enquanto instituição que dita as formas e torna-se causa e finalidade do trabalho artístico) parece estreitamente ligada ao questionamento da arte em suas concepções mais tradicionais e sua valorização através da permanência museológica. Assim, mais do que a defesa do conceito de cultura artística, Maliévitch posiciona-se contra uma espécie de revisionismo histórico, no qual a arte, através de um sistema de inserção museológico, adquire artificialmente uma legitimação sob o carimbo do governo.

A forma de organização das obras no museu era apontada por Maliévitch como uma questão fundamental na percepção dinâmica dos trabalhos. Segundo tal concepção, ao invés de expor uma cronologia "didática" ou histórica das correntes artísticas seria favorável dispor as telas segundo princípios de contraste, ou seja, colocando lado a lado trabalhos de diferentes tensões pictóricas a fim de intensificar as vivências estéticas do espectador, envolvendo-o em uma dinâmica intelectual, sensível e perceptiva, através da relação entre as obras e deste conjunto com o observador.

Como apontava o artista a este respeito:

(...) as paredes dos museus são superfícies planas sobre as quais devem ser colocadas as obras na mesma ordem que a composição de formas é colocada sobre a superfície plana pictórica, quer dizer que, se

7 K. S. Maliévitch, "L'axe de la couleur et du volume", Izobrazitelnoie iskusstvo (Artes da Representação/Artes Plásticas), Petrogrado, 1919. In MALÉVITCH (1977, p. 72). 
sobre a superfície plana pictórica surgissem séries de formas uniformes, a própria obra debilitar-se-ia em sua intensidade e vice-versa.

Se colocarmos uma série de trabalhos uniformes sobre a superfície plana, obteremos uma linha ornamental, o que anula a força que ela poderia fazer aparecer no meio de confrontações variadas.

É por isso que parece ser mais vantajoso executar a montagem na seguinte ordem: ícone, cubismo, suprematismo, os clássicos, o futurismo - percepção pictórica. ${ }^{8}$

Percebe-se assim, uma oposição à referência expositiva do século XIX - representada pela acumulação caótica de telas sobre as paredes - e a partir do princípio de contraste, a intenção de promover no espectador um estado constante de atenção.

A ausência de molduras ou o emprego apenas de sarrafos (montagem recorrente nas telas dos artistas da época) é outro dado pertinente em tal concepção expositiva, na medida em que a presença da moldura reafirma o caráter unitário e uma espécie de auto-encerramento da obra, a qual se projeta para dentro em uma profundidade ilusória, restringindo a possibilidade de interação ou continuidade perceptiva entre os trabalhos.

Contudo, o Museu da cultura pictórica foi fechado em 28 de agosto de 1928. Parte de suas obras foi enviada às províncias, mas muitos trabalhos foram destruídos por ordem de uma comissão da Galeria Tretiakov, ao serem considerados de "nenhuma importância museológica, nem valor de mercado".

\section{Bibliografia}

CONIO, Gérard, Le Constructivisme Russe, 2 volumes, Lausanne: L’Âge d'Homme, 1987.

HOBSBAWM, Eric et al. (org), História do marxismo na época da terceira internacional: problemas da cultura e da ideologia, vol. IX, São Paulo: Paz e Terra, 1987.

KHAN-MAGOMEDOV, S., Vhutemas-Moscou 1920-1930, 2 volumes, Paris: Editions du regard, 1990.

LUNATCHARSKY, Anatoli, As artes plásticas e a política na U.R.S.S., Lisboa: Estampa, 1975.

MARCADÉ, J. C., L'avant-Garde Russe 1907-1927, Paris: Flammarion, 1995.

L'Avant-Garde Russe - Chefs-D’Oenvre des Musées de Russie, 1905-1925, Musée des Beaux-Arts de Nantes, 30 janvier-18 avril, 1993. (Catálogo da Exposição)

${ }^{8}$ MALÉVITCH, K., op. cit., p. 73. 